\title{
O SABER INCONSCIENTE E O SABER QUE SE SABE NOS DIAS DE HOJE
}

Anna Carolina Lo Bianco

Psicanalista.

Professora do

Programa de Pósgraduação em Teoria Psicanalítica da UFRJ.

RESUMO: Partindo da formalização dada por Lacan a duas formas de discurso em que se organiza o laço social — o discurso universitário e o discurso do psicanalista —, o artigo examina o lugar que o saber ocupa em cada um deles. Enquanto no primeiro o saber ocupa o lugar de agente dominante, no discurso do analista o saber em questão é inconsciente. Em seguida procura tirar as consequências que tal formulação traz para a prática clínica tanto quanto para o ensino universitário da psicanálise. Aponta para o conflito que deve persistir a cada vez que os dois discursos são confrontados, pois desconhecê-lo é desconsiderar os efeitos perturbadores que a suposição de um saber inconsciente coloca em causa. Conclui apontando para a necessidade do saber inconsciente quando se trata do sofrimento e da angústia de um sujeito.

Palavras-chave: discurso universitário, discurso do analista, saber universitário, saber inconsciente, conflito.

ABSTRACT: Unconcious knowledge and knowledge nowadays. The article refers to Lacan's distinction between two forms of discourse - the discourse of the university and the one of the analyst - , to observe the place occupied in each of them by knowledge. Regarding the former knowledge is the dominant agent. As to the second, knowledge is unconscious. The consequences of this formulation are examined concerning both psychoanalytical practice and the academic teaching of psychoanalysis. A conflict that must be taken into consideration each time the two types of knowledge are faced with each other is pointed out. Not taking into account this conflict is to refuse to accept the disturbing effects that the supposition of an unconscious knowledge implies. The article concludes by pointing to the necessity of the supposition of unconscious knowledge whenever suffering and anxiety are at stake.

Keywords: university discourse, analyst discourse, academic knowledge, unconscious knowledge, conflict. 
1 ara situar as ideias aqui articuladas vale mencionar que foram endereçadas realizada atenção para a importância de uma vez mais nos deixarmos tomar pela surpresa de ver uma jornada realizada na universidade, organizada pela universidade, ao mesmo tempo dirigir-se à psicanálise e aos que se encarregam de exercê-la. Considerava fundamental que não se tomasse essa característica do evento como dada; que não se 'naturalizasse' a relação entre a psicanálise e a universidade. Via ali a oportunidade de nos perguntarmos sobre o lugar que ocupa o saber inconsciente por relação aos saberes constituídos na cultura hoje. Tinha em vista, ademais, a clivagem entre um saber que vindo do Outro é revelado, não domesticável, implicando por suas características uma relação transferencial e um saber que sofre a incidência que desde Galileu rompe com o saber divino, transferindo-o para o jogo de um algoritmo formalizado (LE BULLETIN, 2007). Reconhecia ali um amplo campo de onde poderíamos interrogar a presença da análise e do corpo conceitual produzido pela psicanálise em meio aos saberes que nos informam e que caracterizam a cultura ocidental como uma cultura científica, cujos desdobramentos merecem atenção. Situávamo-nos em um campo que, ainda que localizado na universidade, não se limitava a ela, estendendo-se por quase todas as esferas da vida cotidiana que nos habitam.

Para além de constatar as diferenças e sem pretender tampouco lamentar com nostalgia a laicização progressiva dos saberes da cultura, é desse ponto que passamos a examinar as exigências contidas nas condições que permitem um saber inconsciente como um saber necessário (LACÔTE-DESTRIBATS, 2007). Temos em mente o passo que, ainda que traga a dimensão de impossível, aponta para a necessidade de fazer surgir a verdade do desejo como resposta ao desespero e à angústia quando estes ameaçam a continuidade da circulação da palavra e da vida sustentada por ela.

Começamos pelo que tem aparência de um desvio do que temos a tratar, mas que, no entanto, está na base de toda a teia de mal-entendidos em que o saber inconsciente é tomado: a psicanálise se ensina na universidade, pois ela não lida com algo inefável, que não possa ser conceituado e tomado como material a ser ensinado. Ela lida com “representações corretas”, afirma Lacan (1962-1963/2004, p.101) citando Freud (1933/1990), e a universidade está instrumentada para tornar público de forma "fiel, precisa e escrupulosa" o saber conceitual da psicanálise (MELMAN, 1999, p.60). A psicanálise pode ser enunciada como um saber que se articula em “definições corretas”, que devem ser ensinadas de

\footnotetext{
${ }^{1}$ Realizada em outubro de 2008, em evento conjunto Ufes/UFRJ/Université de Paris-Est.
} 
maneira rigorosa e ganham seu peso por se articularem por sua vez em uma teoria que lhes dá sentido (LACAN, 1968-1969/2006, p.19). É assim que ela tem um lugar na universidade, a qual irá desempenhar a tarefa que lhe é própria - a de transmitir conhecimentos. É da vocação da universidade e de sua competência, como de resto acontece com os conteúdos de várias disciplinas, veicular obras, pesquisas, trabalhos, e não seria diferente com os de Freud, de Lacan e de alguns outros que tratam da análise.

No entanto, se essa é de fato uma característica inequívoca da psicanálise, o que marca a sua diferença de outros saberes e a singulariza de forma crucial, é justamente algo que a afasta de maneira abissal e definitiva desses mesmos saberes: a psicanálise concerne a um saber que não se sabe. Essa fenda que se abre pela introdução do inconsciente, é claro, não poderia ser sem consequências igualmente profundas e é por ela mesma que emergem os paradoxos que vemos perpassar a psicanálise nos lugares em que em seu nome algo se exerce, seja no ensino universitário, em seu sentido mais estrito, na divulgação de seus princípios ou no exercício mesmo da clínica.

Vale dizer, a psicanálise encontra-se por sua própria constituição numa relação de junção/disjunção com os demais saberes. A consequência imediata a ser retirada dessa constatação é que seja o que for que se faça, dizendo respeito à análise, exige que se leve em consideração o conflito que daí emerge: se de um lado ela não é um saber como os outros, de outro ela não pode ser sem sua referência a eles.

Justamente, no entanto, é na ênfase em sua face de saber a ensinar que a maior parte do que se manifesta como psicanálise ganha publicidade e passa a ser comunicada nas diferentes instâncias em que está presente. E neste âmbito ela pode ser tomada como saber articulado de uma vez por todas, disponível para ser "aplicado" a um sem número de diferentes objetos. É nesta recusa quase total dos efeitos do corte que a instaura, que vemos muitas das condições do que é ensinado como psicanálise se firmar. Há, sem dúvida, um pensamento sobre o inconsciente, mas este, mantendo-se na esfera do pensar, evita em suas formulações os efeitos que seriam provados pela incidência, nesse próprio pensar, da realidade do inconsciente. Esse pensamento sobre o inconsciente visa ao desenvolvimento adequado da teoria psicanalítica, o que pode ser conseguido com mais ou menos perícia, mais ou menos brilhantismo e inteligência por aqueles que se aplicam a fazê-lo. Mas, sobretudo, ele leva a que se reconheça a vitória de Pirro dada pelo sucesso de tornar a psicanálise mais aceitável e acorde aos demais saberes contemporâneos. Ponto em que vale lembrar Freud, que confessava sua desconfiança cada vez que as resistências a seus achados eram vencidas. Na base de seu afastamento de Jung, por exemplo, não se encontra alguma vocação antidemocrática ou autoritária ou uma intolerância especial a posições que diferiam 
da sua. Considerava apenas que não havia motivo de orgulho na aceitação da psicanálise quando o que ela trazia de radical — "o fator sexual” — era retirado de sua elaboração teórica (FREUD, 1914-1996, p.56).

É importante, nesse ponto, recorrermos à formalização dada por Lacan (1969-1970/1992) sobre o que consideramos os efeitos da suposição de um inconsciente e suas vicissitudes na experiência, seja no âmbito universitário, seja fora dele ou ainda na própria prática clínica. A reflexão lacaniana nos fornece os meios para continuarmos a estabelecer com o que a psicanálise está confrontada por se dirigir ao sujeito e por visar ao sofrimento e à angústia que o afastam de seu desejo.

Para falar das diferenças entre o saber do analista e o saber universitário, que como visto não se resume ao que é veiculado apenas na universidade, Lacan (1969-1970/1992) propôs as fórmulas dos discursos universitário e do analista. Em cada um o saber ocupa um lugar diferente. Enquanto no discurso universitário o saber está no comando e o coloca em movimento, no discurso do analista esse saber fica, podemos dizer, em reserva. São os lugares ocupados em cada um dos discursos que darão ao saber suas características. Um será o saber que sabemos, outro o saber que não se sabe, isto é, o saber que nos comanda e regula nosso funcionamento pulsional, nossa apreensão da realidade, nossa relação ao outro, à lei, ao desejo. O discurso no analista, insistimos, não dispensa o saber, ele não é sem o saber; o ato do analista não deixa de passar pelo saber (LACAN, 19671968/2001). Mas, não é pelo saber que ele causa que o sujeito virá a encontrar com seu desejo. O saber não está no comando quando se trata do discurso do analista. Logo, levarmos o saber analítico para a universidade ou fazê-lo ir ao encontro do discurso universitário é uma impossibilidade em seus termos. Da mesma maneira, não há no discurso universitário a possibilidade de encontro com o saber inconsciente e isso é quase um truísmo. Como é um truísmo afirmarmos que, apesar de todas as diferenças que vimos apontando, encontramos a psicanálise sendo ensinada na universidade quase na mesma proporção em que ela é exercida na clínica.

É desse ponto que voltamos a questionar o que é do saber inconsciente, do saber que não se pode saber todo, quando somos tomados pelo discurso universitário.

Ora, encontrarmos o saber da psicanálise no âmbito em que, por excelência, se exerce o discurso universitário, sendo convidado a ocupar, portanto, o lugar de comando que é o do saber nesse que se tornou o discurso hegemônico em nosso tempo, certamente não será sem consequências para a própria psicanálise. É neste ponto que podemos situar uma das impossibilidades quando se depara com o saber universitário - o que não é sem relação também com o que chamamos antes de um ponto paradoxal de junção/disjunção entre os saberes. 
O progresso inexorável que põe em funcionamento o saber universitário, o encontramos em um movimento que excede suas próprias intenções, visando por vezes a apenas 'contribuir' para sua completude, a realizar a promessa de tudo situar sob a sua égide e de tudo se apropriar. Saber acéfalo e hegemônico pelo menos para a parte culta das sociedades, mas não apenas para elas. Pois qualquer operação comandada por este saber em qualquer esfera do cotidiano é de imediato justificada, credenciada e legitimada. Esse é o saber que veicula os achados científicos que informam as práticas cotidianas. Qualquer exemplo que tomemos nos mostra a que estamos apensos quando se trata dele. É um saber que uma vez estabelecido não coloca mais em dúvida nada que venha dele, mesmo que ele se considere a si próprio como mutável, em franco progresso, em busca do avanço e do aumento, a cada vez, de seu poder totalizador.

Retomando a afirmativa de que a psicanálise produz conceitos ensináveis e está na universidade, e que ela é o saber inconsciente, que não se sabe, que não se chega a saber, avançamos agora para considerar que ela está em direção oposta à da marcha do saber universitário.

O que fornece, pois, a garantia de que o saber inconsciente e o saber universitário se articularão de maneiras diferentes e terão consequências distintas é o lugar que ocupam em cada discurso. É, em última instância, o discurso próprio a cada um. Esse lugar não pode não deixar marca no que terá sido a constituição do próprio saber. Torna-se então crucial que a distinção entre os dois discursos seja mantida para que um saber que podemos, mais ou menos apropriadamente, chamar analítico não perca o traço de saber inconsciente que o constitui.

Porém, tal distinção muitas vezes não é reconhecida, seja no ensino universitário, seja mesmo na prática clínica. Como dissemos, isso não é sem consequências para o que passa a ser entendido como psicanálise a partir daí, e para o que vem a ser a análise quando se estabelece uma continuidade entre o saber inconsciente e o saber universitário. Aqui podemos perguntar o que mantém do analítico a intervenção que, na clínica, tem como objetivo a transmissão de conhecimento ao analisante, seja acerca de suas motivações, seja acerca de seu mal-estar ou sofrimento - , mesmo que esta venha travestida das formas mais sofisticadas de "interpretação analítica”.

O desconhecimento da distinção entre os discursos e os lugares que neles ocupam o saber traz ainda outra questão, talvez mais complexa de ser circunscrita, mas que também aponta para os obstáculos confrontados pela relação da análise com o discurso universitário. É importante nesse ponto descermos aos exemplos e tomá-los pelo que são: condutas exemplares de como se absorve o pensamento universitário na prática da análise. São frequentes na prática clínica as derivações imediatas de quantas reflexões — sobre as condições do sujeito, 
seus padecimentos, seus desencontros — forem feitas principalmente pelo pensamento social e filosófico. O que encontramos é a tentativa daqueles clínicos que, orgulhosos por serem bem-pensantes, independentes, autônomos, se acreditarem no direito de fazer seu próprio trilhamento pelas vias mal reconhecidas da invenção freudiana. São comuns os expedientes ad hoc, as reformulações ligeiras e as soluções rápidas para lidar com problemas propriamente clínicos duramente enfrentados por Freud durante décadas. Os mesmos reconsiderados em todas as suas implicações por Lacan, que os retomando irá reinscrevê-los, não sem um incansável trabalho para refundação e aggiornamento de uma práxis rigorosa que venha a fazer jus ao que foi proposto pelo gênio de Freud. Ou seja, não é sempre que é observado o esforço gigantesco de Freud para conceber uma prática clínica ao mesmo tempo que teorizava sobre ela, num movimento de ida e vinda, da teoria para a prática e dessa de volta à teoria. O mesmo se passa com o trabalho de uma vida inteira de Lacan em seu ensino.

Portanto, o que vemos ser a condição de o saber na análise poder ser tomado em sua característica de conhecimento, cujo poder de articulação teórica é da mesma envergadura que qualquer outro saber sobre um objeto suposto universal — o sujeito — é a própria condição de descaracterização do que vem a ser o saber para a psicanálise. É no momento em que se pode tomar a psicanálise apenas pelo que ela traz de pensamento sobre as condições do sujeito em sua presença no mundo ou sobre as condições de produção desse sujeito, como se ela pudesse existir independente de sua práxis, que se a faz equivaler a outros pensamentos. Nesse momento mesmo, o que a psicanálise implica de essencial que é a ética, que vem a ser ela própria, é deixado de lado.

Não se trata, é óbvio, de sequer vislumbrarmos que tais saberes possam ser desconsiderados, eles que consistem e que dão forma à própria configuração do mundo em que nos movemos. No entanto, Freud fez cair sobre esses saberes uma "lâmina cortante" que fez nascer uma práxis nova. A novidade, nunca é demais repetir, se centrava no real que naquele mesmo momento se instaurava. $\mathrm{Na}$ invenção de algo que, se existia anteriormente, dele ninguém sabia - o saber inconsciente. E, para realizar o campo aí aberto, Freud se separa de todo o conhecimento ao qual estivera inteiramente submetido. Introduz, no que irá construir daí em diante, a escuta do sintoma histérico e é pari passu com essa escuta que inventará a psicanálise que por isso mesmo concebe simultaneamente como uma metodologia de investigação e uma operação de cura.

É, pois, no mesmo momento em que a teoria psicanalítica é reconhecida qua teoria e destituída de sua práxis, em que ela se instala entre todas como um saber que articula de forma rigorosa seus conceitos, é nesse mesmo momento que encontra as condições para que deixe de causar os efeitos mesmos que a constituíram como a invenção que se pretendia a peste no pensamento ocidental e passa a ser 
mais um pensamento entre os outros. E, corolária dessa independentização, dessa autonomia da teorização vêm as inevitáveis “clínicas”, que dispensando a difícil elaboração freudiana se acreditam possíveis. Porque justamente se concebe um saber autônomo, desvinculado de sua prática, porque não se toma a articulação psicanalítica como uma práxis é que muitos psicoterapeutas creem poder fazer as suas próprias "experiências clínicas”, em que tomam contribuições de vários autores e de uma maneira que valorizam chamando-a de "intuitiva" improvisam em suas práticas.

O movimento de tornar a psicanálise um conhecimento com regras que lhe conferem consistência interna, que segue uma ordem necessária, que vai do desconhecido ao conhecido, é um movimento que, contrário à própria psicanálise, deixa de fora o sujeito que nela se vê dividido exatamente porque encontra com um saber que o ultrapassa e que é o saber inconsciente ao qual está submetido. Com o lugar de agente ocupado pelo saber no discurso universitário, ao contrário, o sujeito será aquele que será objetalizado como conhecimento, sua posição é a daquele que extrai seu gozo do resultado da operação em que o saber toma um objeto para compreendê-lo. Nessa relação que se estabelece entre o sujeito e o saber está caracterizada a cena atual que nos permite conceber um "gozo dos conhecimentos" em que, a cada vez, se trata de obter uma rentabilidade a mais imediata possível (BALLANGÉ, 2007, p.23). Não é difícil identificarmos aí uma linha de continuidade com a promessa de conhecimento ilimitado que nos é ofertada pela internet.

Neste ponto, voltemos ao que mencionamos no início do presente artigo. Não estamos mais frente a um saber revelado que vem do Outro, que nos coloca o enigma de nosso próprio desejo e a quem, por conseguinte, endereçamos um pedido - a quem nos ligamos por um laço transferencial. Estamos agora frente a um grande Outro Google que nos garante esse saber - implicando uma relação diferente com a alteridade, que se enfraquece por ser considerada parceira na demanda. Ou seja, se algum pedido é feito ao Outro, a resposta vem imediata e plena e não comporta um enigma. Ou seja, encontramo-nos liberados daquilo que nos pode colocar em suspensão e causar o desejo de saber. Trata-se agora de um Outro que ao responder "não deixa a desejar" (BALLANGÉ, 2007, p.24). Se algum pedido ainda assim persiste, é endereçado ao computador: o parceiro ideal.

Não se trata, no entanto, como já frisamos, de viver da nostalgia do que teremos perdido. Vale aqui seguir a observação de Lacôte-Destribats (2007) que, ainda que reconhecendo as vias traçadas pelos desdobramentos do saber universitário, procura as condições de possibilidade que permitam um saber que considera necessário, quando se trata do sofrimento e da angústia do sujeito. Vale dizer, um saber que suporta a necessidade de fazer surgir a verdade do desejo como resposta 
ao desespero que impede a palavra de circular e dar lugar ao sujeito que é seu efeito. Um saber que depende de certo tempo para que se decante tudo o que implica o contrário do saber imediatamente disponível que nos chega pela rede de informações que nos cerca. Porque este último se empenha em encurtar os trajetos lentos, organizados por achados que traziam de início a desorganização, achados que, entretanto, iam deixando traços aos poucos para que com eles se constituíssem os saberes. Atualmente demandamos os resultados e imediatamente recebemos como que prescrições, códigos de conduta, protocolos com passos e tarefas a serem seguidos.

Derivamos daí uma "pressa prescritiva” que não oferece lugar para o saber inconsciente (LACÔTE-DESTRIBATS, 2007, p.32), contrariamente ao que foi o caminho de Freud. Ele introduziu no conhecimento científico — esse mesmo dos códigos e dos protocolos - uma inflexão que corta o seu curso e instaura uma nova práxis. Para desenvolvê-la foi preciso um longo tempo em que o trabalho de escuta e inscrição do inconsciente ia sendo acompanhado do tratamento dos casos. Voltas em que encontrava o fracasso que o fazia avançar. Portanto, o avanço exigia um tempo para que o saber-fazer fosse nutrindo o saber, no mesmo passo em que esse saber era elaborado para dar garantia à práxis que se inventava. Movimento muito distinto do que vemos sendo instalado nas "clínicas", mesmo as que se dizem psicanalíticas, que apressadamente se instalam com vistas a assegurar os bons resultados, o sucesso, e o apaziguamento ligeiro da angústia, através de uma conduta prescrita e prescritiva.

Sob pena de fugirmos um pouco da questão central que aqui nos concerne, a que diz respeito ao lugar do saber em cada um dos discursos que vimos circundando e, tendo em vista os termos em que se dispõem as relações do sujeito com o saber, cabe a pergunta: que lugar para a psicanálise em tal panorama? A invenção feita por Freud e o trabalho que, mantendo as raízes inauguradas com ele, foi avançado por Lacan mostram os sulcos a serem trilhados.

Vemos que as condições de relação do sujeito com o Outro atualmente apenas exacerbam as que se instalam na via aberta pelas primeiras concepções de um sujeito que conhece e é consequência de seu próprio pensamento. Estamos no campo mesmo em que a invenção de Freud se exerceu e se encontrou com o conflito que lhe é inerente. Podemos mesmo afirmar que não se trata sequer de procurar conceitos novos que dariam conta do que encontramos como desafios (MELMAN, 2002). É com os mesmos recursos dados pela doutrina que temos que contar. E se a doutrina "não se tornou vã ou caduca” resta somente um "esforço de radicalização a inscrever” (LACÔTE-DESTRIBATS, 2007, p.35). Diríamos, um esforço de mais ainda fazer valer a invenção freudiana do inconsciente. 


\section{REFERÊNCIAS}

BALLANGÉ, V. (2007). À consommer avec modération. Le Bulletin, 3, p.22-26.

FREUD, S. (1933-1990). 32ª Conferência. Angústia e Vida Pulsional, in , Sigmund Freud. Obras completas, tradução de J.L.Etcheverry, v.22, p.75-103. Buenos Aires: Amorrortu.

. (1914-1996). Contribución a la historia del movimiento psicoanalítico, in Sigmund Freud. Obras completas, v.XIV, p.1-64. Buenos Aires: Amorrortu.

LACAN, J. (1968/1969-2006). O Seminário Livro XVI. De um Outro ao outro. Rio de Janeiro: Jorge Zahar Editores.

(1962/1963-2004). Le Séminaire livre X. L’angoisse. Paris: Seuil.

(1969/1970-1992). O Seminário Livro 17. O avesso da psicanálise. Rio de Janeiro: Jorge Zahar Editores.

LACÔTE-DESTRIBATS, C. (2007). Une antecipation nécessaire. Le Bulletin, 3, p.31-35.

LE BULLETIN. (2007). Présentation. Le savoir désenchanté? Le Bulletin, 3, p.9-12.

MELMAN, C. (2002). L'homme sans gravité. Jouir à tout prix. Paris: Denoël. (1999). Retour à Schreber. Séminaire 1994-1995. Paris: Éditions de l'Association Freudienne Internationale.

Anna Carolina Lo Bianco

aclobianco@uol.com.br 